\title{
Microstructure and Mechanical Properties of a High-Mn TWIP Steel Subjected to Cold Rolling and Annealing
}

\author{
Alexander Kalinenko ${ }^{1}$, Pavel Kusakin ${ }^{1}$ (D) , Andrey Belyakov ${ }^{1}$ (D), Rustam Kaibyshev ${ }^{1}$ \\ and Dmitri A. Molodov ${ }^{2, *}$ \\ 1 Laboratory of Mechanical Properties of Nanostructured Materials and Superalloys, \\ Belgorod State University, Pobeda 85, Belgorod 308015, Russia; lexs4@mail.ru (A.K.); \\ kusakin@bsu.edu.ru (P.K.); belyakov@bsu.edu.ru (A.B.); rustam_kaibyshev@bsu.edu.ru (R.K.) \\ 2 Institute of Physical Metallurgy and Metal Physics, RWTH Aachen University, Kopernikusstraße 14, \\ Aachen 52056, Germany \\ * Correspondence: molodov@imm.rwth-aachen.de; Tel.: +49-241-8026873
}

Received: 20 November 2017; Accepted: 14 December 2017; Published: 18 December 2017

\begin{abstract}
The structure-property relationship was studied in an Fe-18Mn-0.6C-1.5Al steel subjected to cold rolling to various total reductions from $20 \%$ to $80 \%$ and subsequent annealing for $30 \mathrm{~min}$ at temperatures of 673 to $973 \mathrm{~K}$. The cold rolling resulted in significant strengthening of the steel. The hardness increased from 1900 to almost $6000 \mathrm{MPa}$ after rolling reduction of $80 \%$. Recovery of cold worked microstructure developed during annealing at temperatures of 673 and $773 \mathrm{~K}$, resulting in slight softening, which did not exceed 0.2. On the other hand, static recrystallization readily developed in the cold rolled samples with total reductions above $20 \%$ during annealing at 873 and $973 \mathrm{~K}$, leading to fractional softening of about 0.8 . The recrystallized grain size depended on annealing temperature and rolling reduction; namely, it decreased with a decrease in the temperature and an increase in the rolling reduction. The mean recrystallized grain size from approximately 1 to $8 \mu \mathrm{m}$ could be developed depending on the rolling/annealing conditions. The recovered and fine grained recrystallized steel samples were characterized by improved strength properties. The yield strength of the recovered, recrystallized, and partially recrystallized steel samples could be expressed by a unique relationship taking into account the fractional contributions from dislocation and grain size strengthening into overall strength.
\end{abstract}

Keywords: high-Mn TWIP steel; cold rolling; annealing; recovery; recrystallization; strengthening

\section{Introduction}

High-Mn austenitic TWIP/TRIP steels have aroused a great interest among materials scientists and engineers because of their outstanding strength-ductility combinations [1-4]. These steels are considered as the most promising materials for various structural applications in automobile and building industries [5,6]. In general, the mechanical properties of steel semi-products depend on their microstructure, including dislocation substructures, which can be substantially varied by using appropriate regimes/conditions for the applied thermo-mechanical treatment. Therefore, studies on the microstructure/substructure evolution during thermo-mechanical treatment are of great practical importance.

Presently, the most efficient processing methods for production of large-scale steel products involve plate or caliber rolling combined with some heat treatment. The deformation microstructures that develop in steels subjected to rolling depend sensitively on the processing conditions [7-9]. Cold rolling is accompanied by strain hardening, the rate of which gradually decreases with increasing 
the total rolling strain [10]. The well-developed subgrains can be obtained by warm rolling that is accompanied by dynamic recovery. Dynamic and/or post-dynamic recrystallization during hot working may lead to the uniform microstructure with the mean grain size depending on deformation conditions [9]. Regarding high-Mn austenitic steels, such steels are commonly characterized by a low stacking fault energy (SFE), which controls the development of deformation twinning and/or martensitic transformation leading to twinning- and/or transformation-induced plasticity [11,12]. On the other hand, low SFE hampers any dislocation rearrangements and, thus, slows down the dislocation recovery processes. Therefore, high-Mn austenitic steels are hardly susceptible to dynamic recovery under warm rolling conditions, and the work hardened microstructures remain almost unchanged up to high temperatures sufficient for recrystallization development $[13,14]$.

High-Mn austenitic steels exhibit significant strain hardening owing to increasing the dislocation density during cold-to-warm working [13-15]. The dislocation strengthening leads to remarkable increase in both the yield strength and the ultimate tensile strength [15]. On the other hand, strengthening by cold-to-warm working is generally accompanied by a degradation of plasticity. The total elongation may drop to a few percent after large strain cold working $[16,17]$. The mechanical properties of work hardened high-Mn steels can be improved by an appropriate heat treatment. Beneficial combination of the strength and ductility can be obtained by large strain cold rolling followed by a recrystallization annealing. The combination of large strain deformation with subsequent annealing may result in the development of special microstructures. Those are partially recrystallized microstructures, where recrystallized grains are surrounded by work hardened portions, and/or ultrafine grained microstructures. Both partially recrystallized and completely recrystallized ultrafine grained microstructures may provide useful strength-ductility combinations.

The aim of the present paper is to study the effect of the rolling strain and subsequent annealing at elevated temperatures on the development of recovery and recrystallization in an advanced $18 \% \mathrm{Mn}$ austenitic steel. Contributions of the dislocation strengthening and the grain size strengthening into the yield strength of the steel with various microstructures including recovered, partially recrystallized, and ultrafine grained ones are particularly addressed.

\section{Materials and Methods}

An Fe-18\%Mn- $0.6 \% \mathrm{C}-1.5 \% \mathrm{Al}$ steel was hot rolled to a total reduction of $80 \%$ and annealed at a temperature of $1423 \mathrm{~K}$ for $1 \mathrm{~h}$ followed by air cooling. Then, the steel samples were cold rolled to total rolling reductions of $20 \%, 40 \%, 60 \%$, and $80 \%$ at room temperature. These cold rolled steel samples were annealed at various temperatures in the range of 673 to $973 \mathrm{~K}$ for $30 \mathrm{~min}$.

The structural investigations were carried out on the sample sections parallel to the normal direction (ND), using a Nova Nanosem 450 scanning electron microscope (SEM, FEI, Hillsboro, OR, USA) equipped with electron back-scatter diffraction (EBSD) analyzer incorporating orientation imaging microscopy (OIM, EDAX Inc., Mahwah, NJ, USA). The SEM specimens were prepared by electro-polishing using a solution of $90 \%$ acetic acid and $10 \%$ of perchloric acid at a voltage of $20 \mathrm{~V}$. The OIM maps of $100 \times 100 \mu \mathrm{m}^{2}$ and $50 \times 50 \mu \mathrm{m}^{2}$ for the cold rolled and annealed samples, respectively, were obtained with a step size of $0.1 \mu \mathrm{m}$. The OIM data points with confidence index below 0.1 were replaced by black dots. The mean grain size $(D)$ and the kernel average misorientation (KAM) were obtained using OIM Analysis 6 software (EDAX Inc., version 6.2.0, Mahwah, NJ, USA). The dislocation density was evaluated by means of KAM as [14]

$$
\rho=1.15 \cdot K A M /(b h),
$$

where $b=0.258 \mathrm{~nm}$ is the Burgers vector and $h=300 \mathrm{~nm}$ is the distance between the measured points in KAM maps. 
The hardness measurements were carried out in order to evaluate the strain hardening and annealing softening. The latter was estimated as [18]

$$
X=\left(H v_{\varepsilon}-H v_{T}\right) /\left(H v_{\varepsilon}-H v_{0}\right)
$$

where $H v_{\varepsilon}, H v_{T}$, and $H v_{0}$ are the hardness of cold rolled, annealed, and initial samples, respectively. The tensile tests were carried out at room temperature and at an initial strain rate of $2 \times 10^{-3} \mathrm{~s}^{-1}$ using an Instron 5882 testing machine (Instron, Norwood, MA, USA). The tensile specimens with a gauge length of $16 \mathrm{~mm}$ and cross section of $1.5 \times 3 \mathrm{~mm}^{2}$ were machined with the tensile axis parallel to the rolling axis.

\section{Results and Discussion}

\subsection{Cold Rolling}

Typical OIM images of the deformation microstructures developed in the high-Mn steel during cold rolling to various total strains are shown in Figure 1. The deformation twins readily develop during cold rolling (Figure 1a). An increase in the rolling reduction leads to an increase in the dislocation density. Correspondingly, the number and misorientation of dislocation subboundaries increase. The misorientation of some deformation subboundaries increases over a critical value, separating low-angle subboundaries and high-angle boundaries. Therefore, these deformation subboundaries are indicated as high-angle grain boundaries on OIM image (Figure 1b). Further rolling is accompanied by the development of deformation microbands involving large lattice distortions (Figure 1c). The microbanding during cold rolling is consistent with previous studies on high-Mn austenitic TWIP steels, which involved numerous microshear bands after $60 \%$ rolling reduction $[16,17]$. The microband density and their thickness increases with straining. After large rolling reduction, the microstructural analysis by OIM becomes difficult because of a large fraction of frequently developed deformation microbands and related lattice distortions.

Cold rolling is accompanied by a significant increase in the hardness (Figure 2). The hardness increases almost two-fold from about 2000 to approximately $4000 \mathrm{MPa}$ after rolling reduction of $20 \%$. The rate of strain hardening gradually decreases during cold rolling. An increase in the rolling reduction to $40 \%$ leads to the hardness of $5000 \mathrm{MPa}$. Further rolling to large total reduction of $80 \%$ results in the hardness of about $6000 \mathrm{MPa}$. Such strain hardening behavior is typical for large strain cold deformation of various structural steels and alloys, when the hardness increases with straining and gradually approaches a saturation level at sufficiently large strains [19].

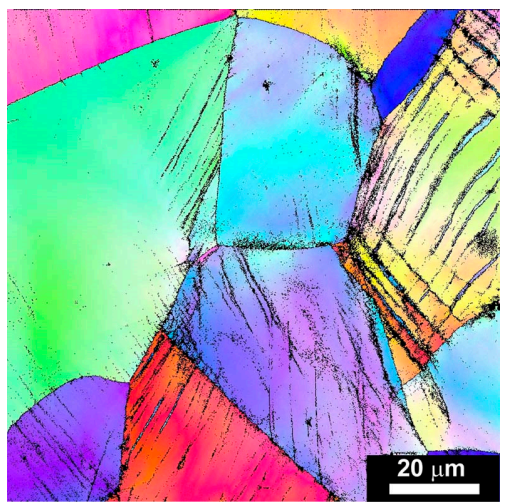

(a)

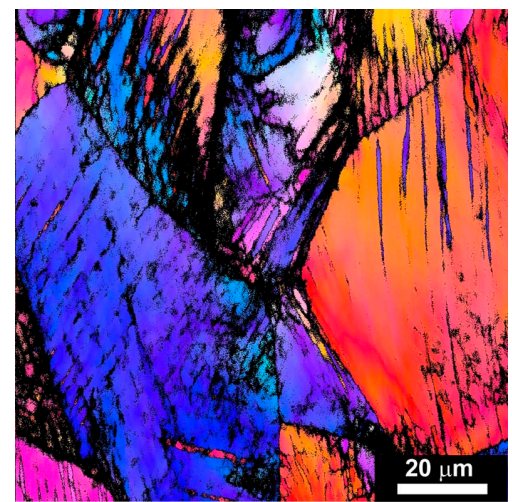

(b)

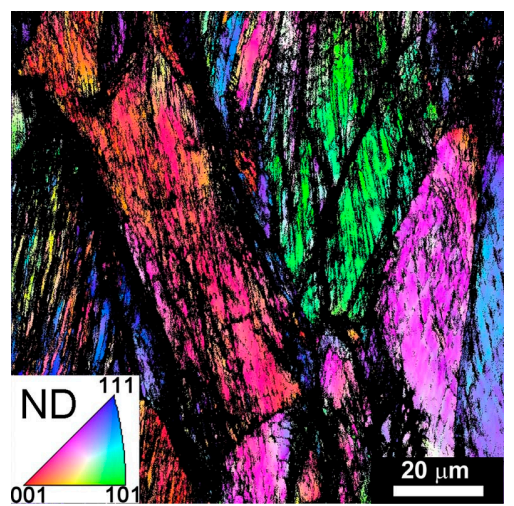

(c)

Figure 1. Deformation microstructures in a high-Mn steel subjected to rolling reduction of $20 \%$ (a); $40 \%$ (b); $60 \%$ (c). Low-angle and high-angle boundaries are indicated by thin and thick black lines, respectively. Color orientations are shown for the normal direction (ND). 


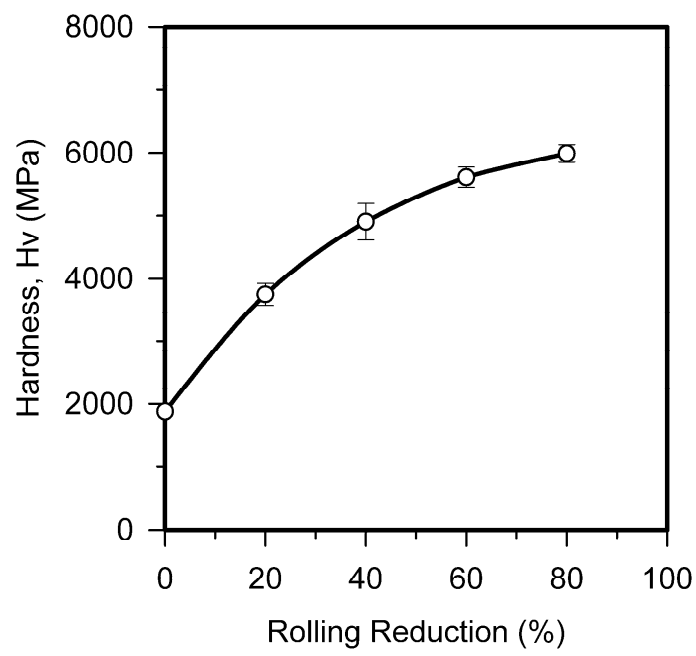

Figure 2. Strain hardening for a high-Mn steel subjected to cold rolling at room temperature.

\subsection{Annealing Behavior}

The isochronal annealing was carried out to investigate the temperature effect on microstructure evolution in the cold rolled high-Mn steel. The range of annealing temperatures and the annealing time were selected to cover the operation of various restoration mechanisms including recovery and recrystallization and, therefore, to obtain variety of annealed microstructures-i.e., recovered, partially recrystallized, and fully recrystallized $[13,14]$. The effect of annealing temperature on the hardness and fractional softening of the present high-Mn steel subjected to cold rolling to various total strains is shown in Figure 3. Two temperature intervals are clearly distinguished by their effect on both the hardness and the fractional softening. Annealing at temperatures below about $800 \mathrm{~K}$ does not result in any remarkable changes in the hardness irrespective of the previous rolling reductions. The corresponding fractional softening does not exceed 0.2 after annealing within this temperature range. In contrast, the hardness drastically drops after annealing at temperatures above $800 \mathrm{~K}$. This change in the hardness is more pronounced in the samples subjected to larger rolling reductions. Except the sample subjected to rolling reduction of $20 \%$, the fractional softening comprises approximately 0.8 after annealing at temperatures above $800 \mathrm{~K}$. The different softening behavior at temperatures below or above $800 \mathrm{~K}$ suggests that different annealing/softening mechanisms operate in these temperature regimes.
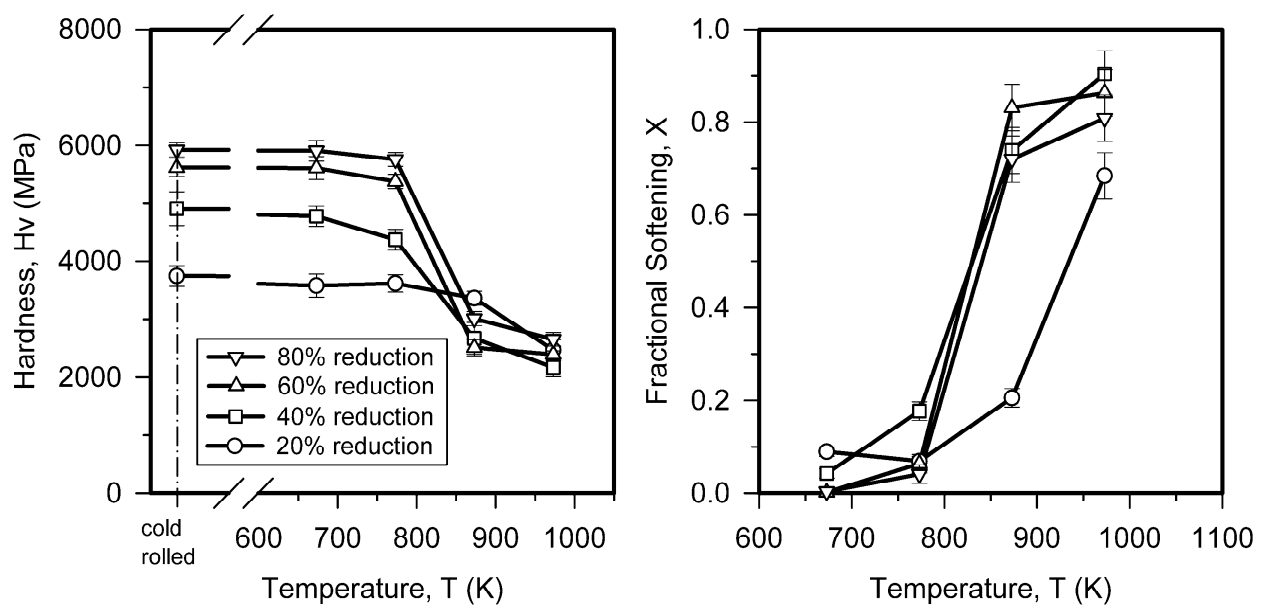

Figure 3. Hardness change and annealing softening for a high-Mn steel subjected to various cold rolling reductions and then annealed for $30 \mathrm{~min}$ at $673-973 \mathrm{~K}$. 
Typical microstructures that evolved in the steel samples after rolling reductions of $20 \%$ and $60 \%$ followed by annealing at a temperature of $773 \mathrm{~K}$ are shown in Figure 4 as OIM micrographs and KAM maps. It is clearly seen that annealing at this temperature is not accompanied by any remarkable changes in the deformation microstructures. It can be concluded, therefore, that static recovery is the only operative softening mechanism in this annealing domain. High-Mn austenitic steels with low SFE have been shown being quite stable against recovery because of large dislocation dissociation spacing [20]. Hence, the larger internal distortions, which were caused by higher dislocation densities in deformation substructures after larger rolling reductions, remain larger after recovery annealing as shown in the KAM maps. On the other hand, annealing at temperatures above $800 \mathrm{~K}$ results in the recrystallization development (Figure 5). An increase in the cold strain accelerates the recrystallization kinetics. The fraction recrystallized comprises about 0.6 in the sample subjected to rolling reduction of $40 \%$ and then annealed at $873 \mathrm{~K}$ (Figure 5a), whereas the completely recrystallized microstructures evolve after annealing at the same temperature following the rolling reductions of $60 \%$ and $80 \%$ (Figure $5 b, c$ ). An increase in the rolling reduction promotes the development of fine grained recrystallized microstructure similar to ordinary primary recrystallization behavior [21]. An increase in the annealing temperature increases the size of recrystallized grains (Figure 5d).
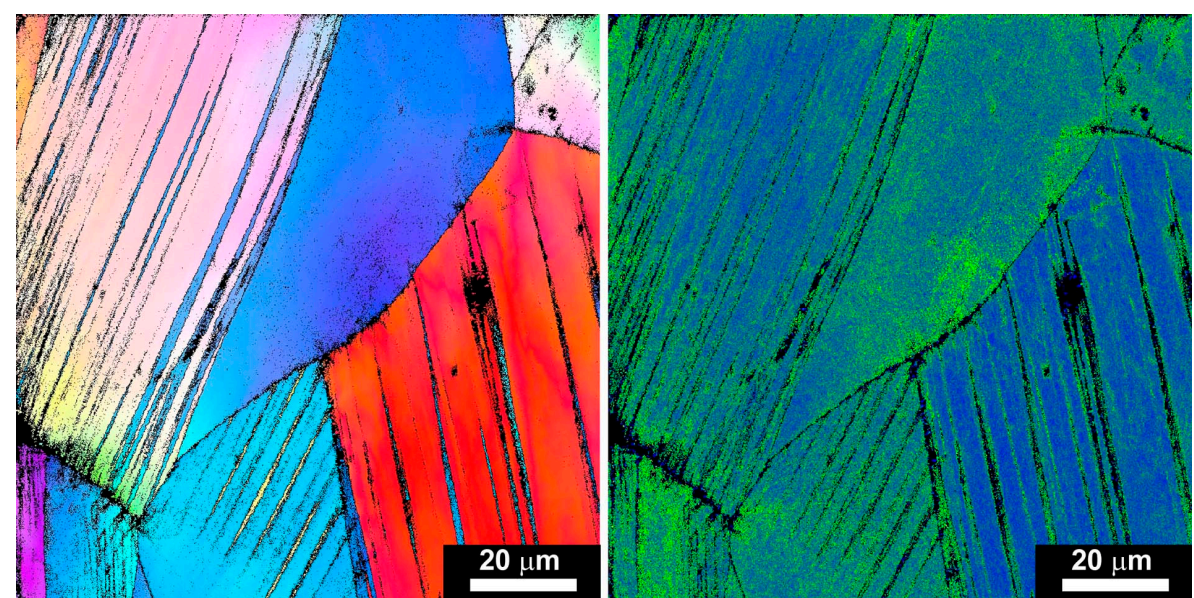

(a)
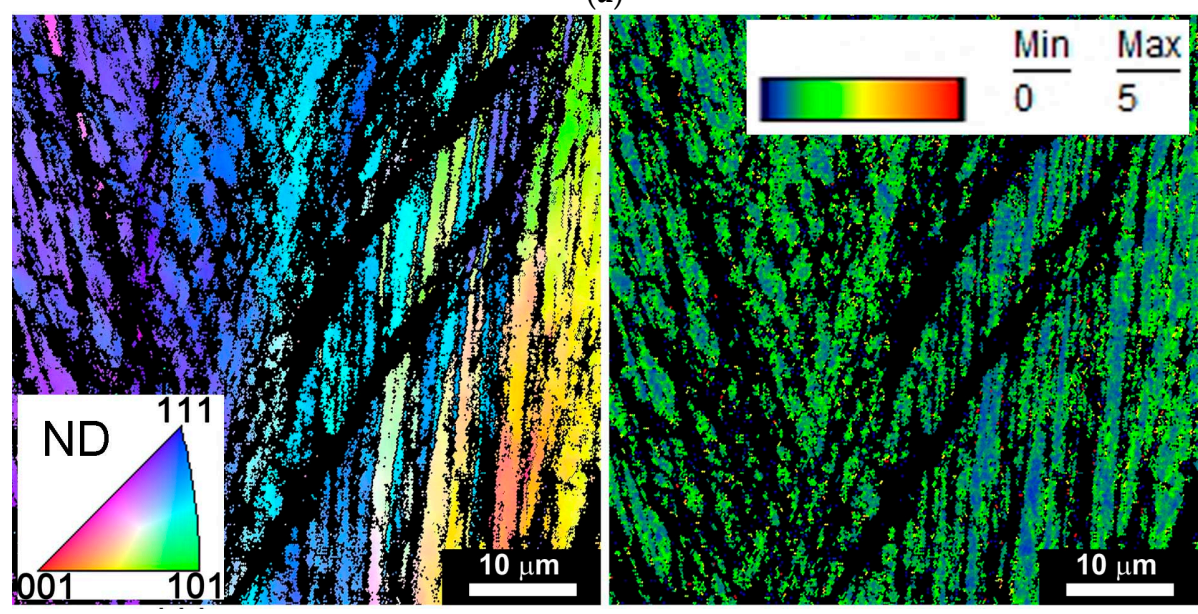

(b)

Figure 4. Annealed microstructures of a high-Mn steel subjected to cold rolling reduction of (a) $20 \%$ or (b) $40 \%$ and then annealed at $773 \mathrm{~K}$. Left-side images are color orientations corresponding to the normal direction (ND), right-side images are KAM maps. Low-angle and high-angle boundaries are indicated by thin and thick black lines, respectively. 
The effect of rolling reduction on the recrystallized grain size and the recovered dislocation density in the high-Mn austenitic steel subjected to cold deformation followed by an annealing is shown in Figure 6. The size of recrystallized grains after annealing at $973 \mathrm{~K}$ remarkably decreases from 8 to $1.6 \mu \mathrm{m}$ with an increase in the rolling reduction from $20 \%$ to $80 \%$. It is worth noting that annealing temperature does not affect the recrystallized grain size substantially. For instance, following rolling reduction of $80 \%$, annealing at $873 \mathrm{~K}$ results in arecrystallized grain size of $1.1 \mu \mathrm{m}$. Similar to the recrystallized grain size, the dislocation density in the recovery annealed samples strongly depends on the preceding rolling reduction. The dislocation density varies in the range of $10^{14} \mathrm{~m}^{-2}$ to $4 \times 10^{14} \mathrm{~m}^{-2}$ in the samples subjected to rolling reductions of $20-40 \%$ followed by annealing at $673-873 \mathrm{~K}$. In contrast, much higher dislocation densities of about $10^{15} \mathrm{~m}^{-2}$ evolve in the samples subjected to rolling reductions of $60-80 \%$ followed by annealing at $673-773 \mathrm{~K}$.

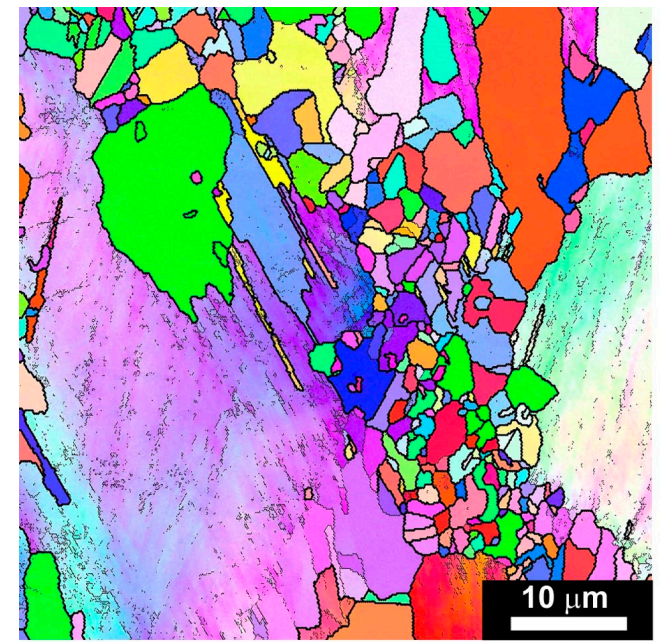

(a)

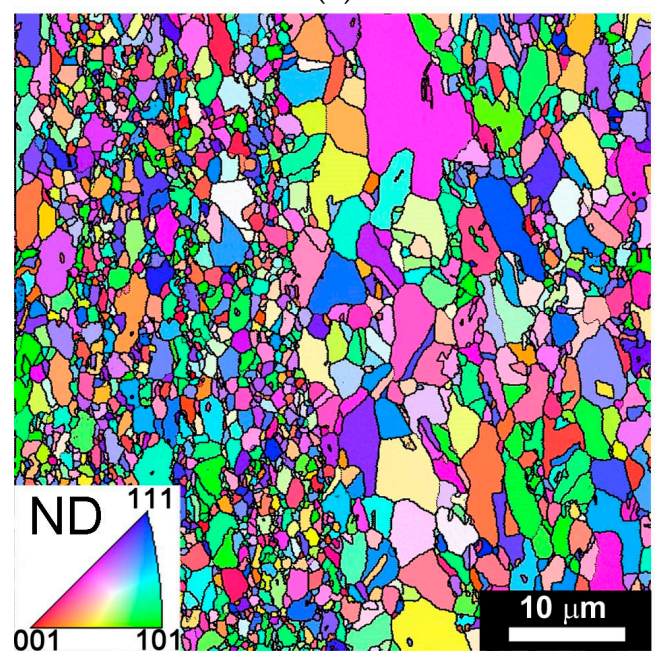

(c)

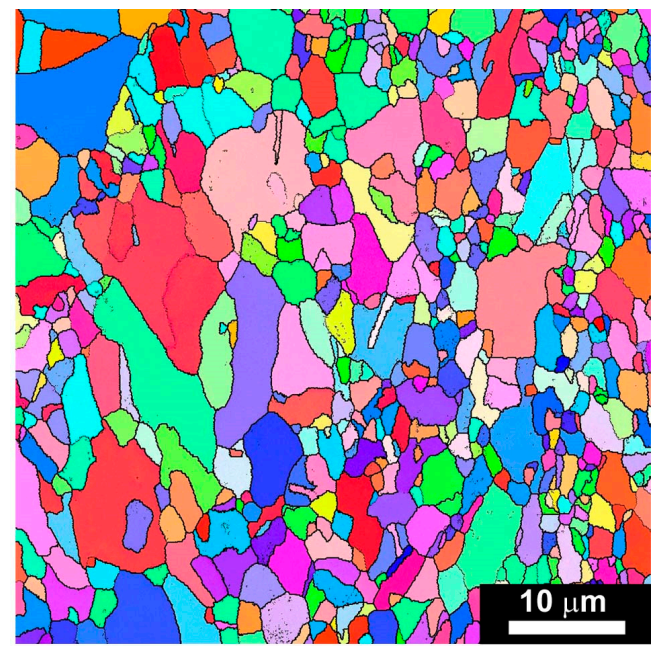

(b)

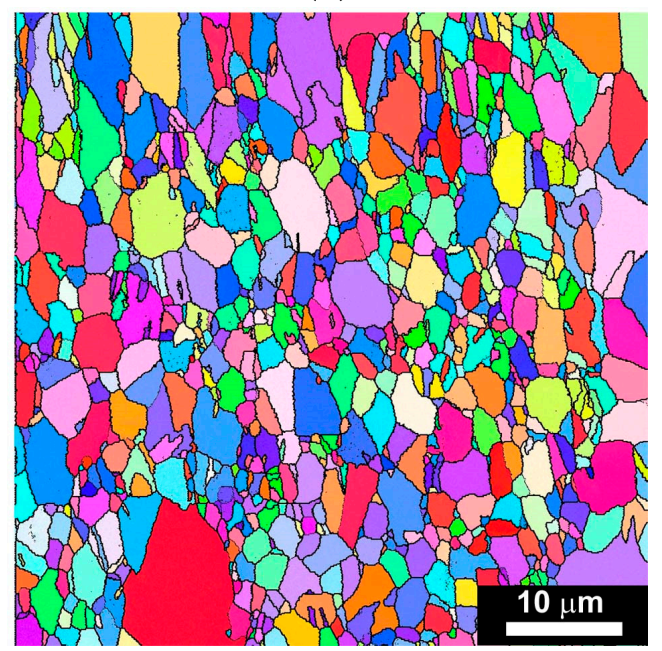

(d)

Figure 5. Annealed microstructures of a high-Mn steel subjected to cold rolling followed by annealing; (a) rolling reduction of $40 \%$, annealing at $873 \mathrm{~K}$; (b) rolling reduction of $60 \%$, annealing at $873 \mathrm{~K}$; (c) rolling reduction of $80 \%$, annealing at $873 \mathrm{~K}$; (d) rolling reduction of $80 \%$, annealing at $973 \mathrm{~K}$. 

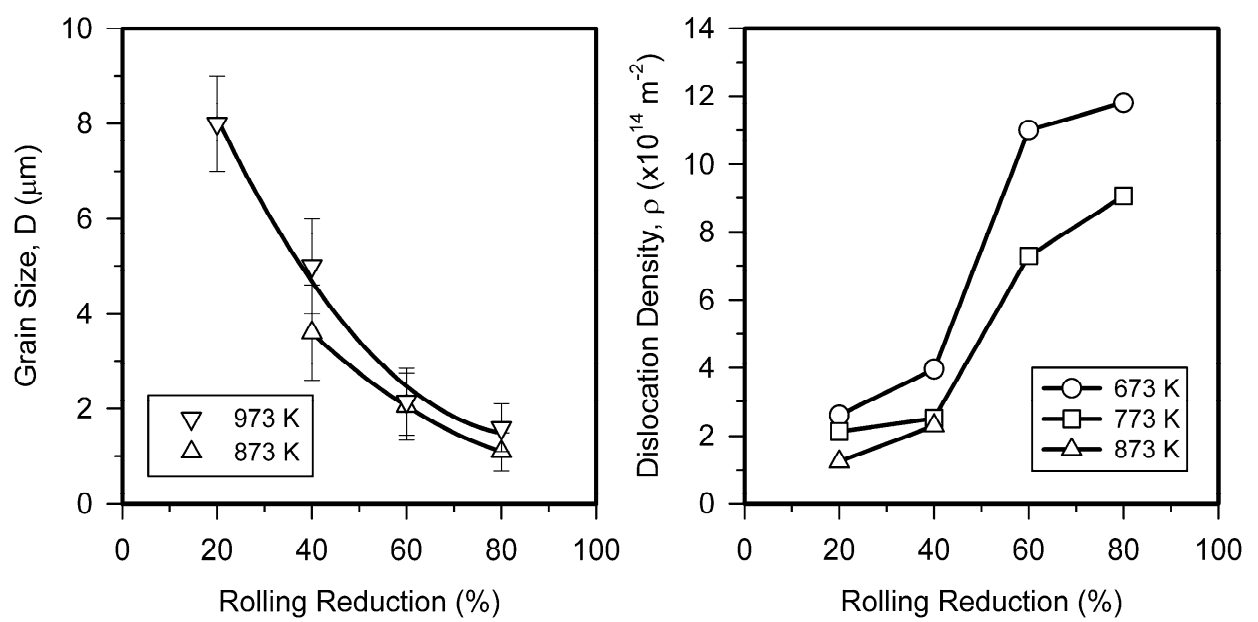

Figure 6. Effect of cold rolling reduction and annealing temperature on the grain size and dislocation density after recrystallization and recovery annealing of a high-Mn steel.

\subsection{Mechanical Properties}

The engineering stress-elongation curves obtained by tensile tests of the high-Mn austenitic steel after cold rolling and annealing are shown in Figure 7. Recovery annealing at temperatures of 673 and $773 \mathrm{~K}$ does not provide significant softening irrespective of the rolling reductions. Therefore, the general shape of the tensile stress-strain curves for the samples annealed at 673 and $773 \mathrm{~K}$ depends remarkably on the previous rolling reduction (Figure $7 \mathrm{a}, \mathrm{b}$ ). The steel samples subjected to relatively small rolling reductions of $20 \%$ and $40 \%$ exhibit increased yield strength of about 700 and $1250 \mathrm{MPa}$, respectively. Following yielding, the strain hardening quickly decreased to some positive value, which remains almost constant up to necking. An increase in the annealing temperature from 673 to $773 \mathrm{~K}$ improves plasticity, although it does not remarkably affect the yield strength and the ultimate tensile strength. The yield strength increases above $1200 \mathrm{MPa}$ after rolling reductions of $60-80 \%$ followed by recovery annealing at 673 and $773 \mathrm{~K}$, whereas the total elongation decreases substantially and does not exceed a couple of percent after rolling reduction of $60 \%$ and $80 \%$ followed by recovery annealing. On the other hand, recrystallization annealing at 873 and $973 \mathrm{~K}$ softens the cold rolled steel samples and significantly improves their plasticity (Figure 7c,d). The strength of the recrystallized steel samples commonly decreases with an increase in the temperature and a decrease in the rolling reduction.

The tensile deformation behavior of the present steels samples is closely related to their microstructures. The dislocation substructures and corresponding strain hardening remain almost unchanged during recovery annealing. Therefore, the tensile behavior of the recovery annealed samples depends mainly on the previous cold strain. In contrast, the mechanical properties of the steel samples after recrystallization annealing depend on the mean grain size. In this case, the rolling reduction affects the strength properties of recrystallized steels through the recrystallized grain size that depends on the recrystallization kinetics, which, in turn, depends on the previous cold strain. The relationship between the yield strength of the steel samples after recrystallization annealing and the recrystallized grain size is represented in Figure 8 as a Hall-Petch type plot. The yield strength $\left(\sigma_{0.2}\right)$ of the recrystallized steel samples obeys an ordinary relationship,

$$
\sigma_{0.2}=\sigma_{0}+k_{y} D^{-0.5}
$$

where, $\sigma_{0}$ is the yield strength of the same material with unlimited grain size and $k_{y}$ is the grain boundary strengthening factor [22,23]. The values of $\sigma_{0}=160 \mathrm{MPa}$ and $k_{y}=355 \mathrm{MPa} \mu \mathrm{m}^{0.5}$ are obtained in the present study. Note here, almost the same $\sigma_{0}$ and $k_{y}$ have been reported in other papers on austenitic steels [13,24-26]. 
The strengthening of the recovered steel samples can be related to their dislocation density similar to other studies on work hardened materials [27-29]

$$
\sigma_{0.2}=\sigma_{0}+\alpha M G b \rho^{0.5}
$$

where $\alpha, M$, and $G$ are a numerical factor, the Tailor factor $(M=3$ is frequently used for face centered cubic metallic materials [30,31]) and the shear modulus, respectively. Here, $\sigma_{0}$ means the strength of dislocation-free recrystallized steel and can be taken as that from Equation (3) for the sake of simplicity. The relationship between the dislocation density, which was evaluated by means of KAM (Equation (1)), and the yield strength of the recovered steel samples is also represented in Figure 8. It is clearly seen that the dislocation strengthening can be expressed by Equation (4) with $\alpha=0.6$. The value of $\alpha$ has been reported varying from about 0.2 to $0.5[14,15,24,30-32]$. Relatively large $\alpha=0.6$ obtained for the present work hardened steel samples may be attributed to an enhanced efficiency of dislocation strengthening in high-Mn austenitic steels with low SFE as well as to somewhat underestimated dislocation density by the KAM values, which are actually associated with excess dislocations of similar Burgers vectors rather than total dislocation density [33]. Then, combining Equations (3) and (4), the yield strength of recovered and recrystallized steel samples including partially recrystallized ones can be expressed as

$$
\sigma_{0.2}=\sigma_{0}+F_{R E X} k_{y} D^{-0.5}+\left(1-F_{R E X}\right) \propto M G b \rho^{0.5}
$$

where $F_{R E X}$ is the fraction recrystallized. The plot in Figure 9 validates the speculation above.

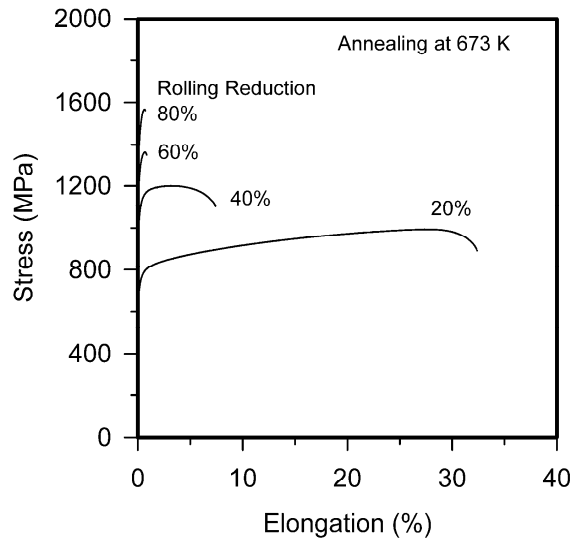

(a)

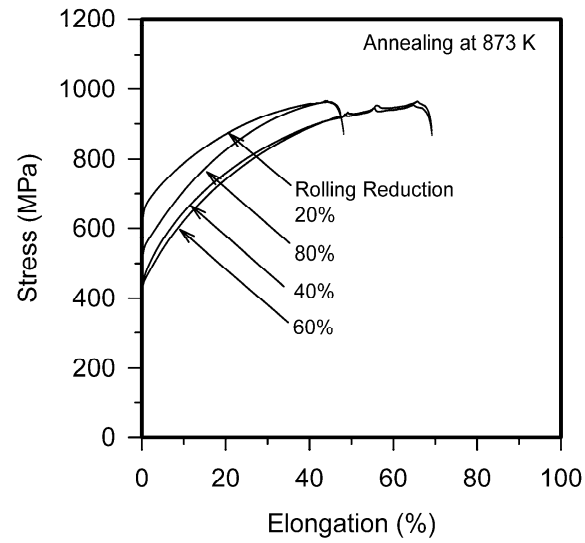

(c)

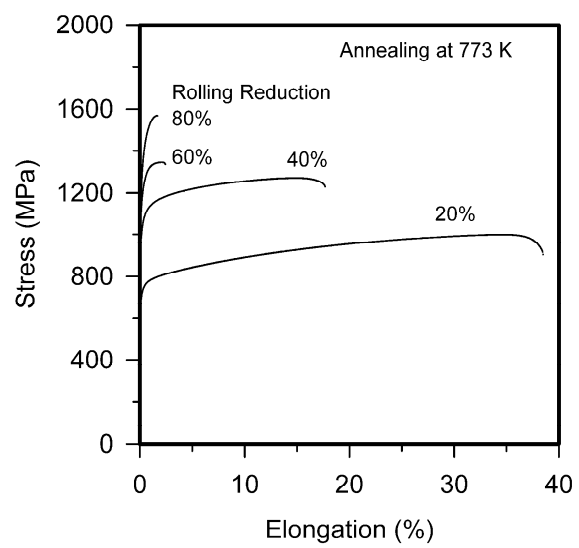

(b)

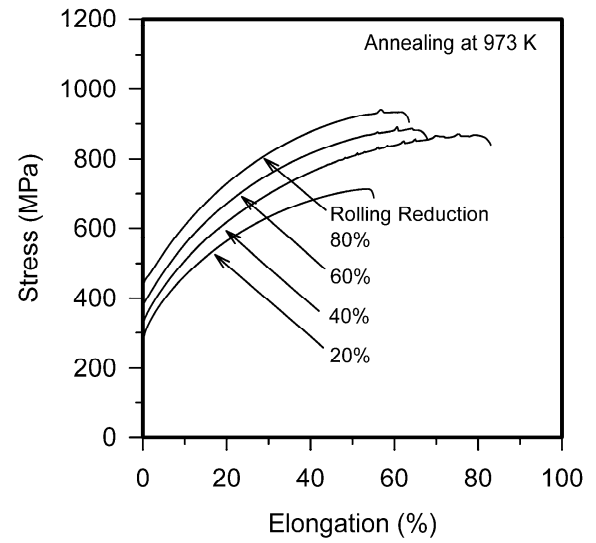

(d)

Figure 7. Engineering stress vs. elongation curves for a high-Mn steel subjected to cold rolling followed by annealing at (a) $673 \mathrm{~K}$; (b) $773 \mathrm{~K}$; (c) $873 \mathrm{~K}$; (d) $973 \mathrm{~K}$. 
The present results suggest that combination of cold rolling with reductions of $20 \%$ to $80 \%$ and annealing at 673 to $973 \mathrm{~K}$ can be used as various advanced thermo-mechanical processing methods to obtain high-Mn austenitic TWIP steel plates with a desired strength and ductility. The required combination of mechanical properties is achieved by the development of appropriate structural state, which may consist of a mixture of various structures including work hardened, recovered, and partially and completely recrystallized ones. An increase in the rolling reduction increases the deformation stored energy and, therefore, promotes the primary recrystallization. It should be noted that the stored energy significantly accelerates the rate of recrystallization nucleation. Hence, the rapid recrystallization nucleation at temperatures close to a critical recrystallization temperature for the steel samples subjected to large strain cold rolling results in beneficial mechanical properties including high strength and large uniform elongation owing to the development of uniform ultrafine-grained microstructures.

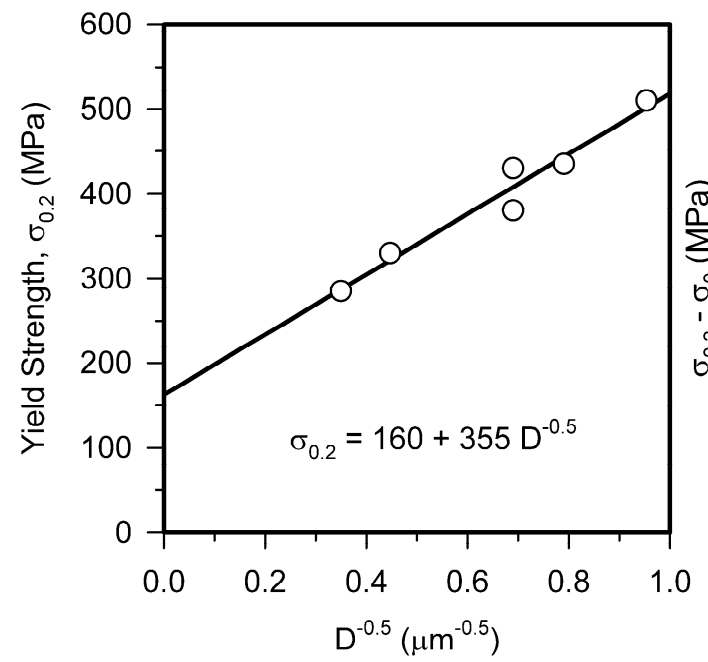

(a)

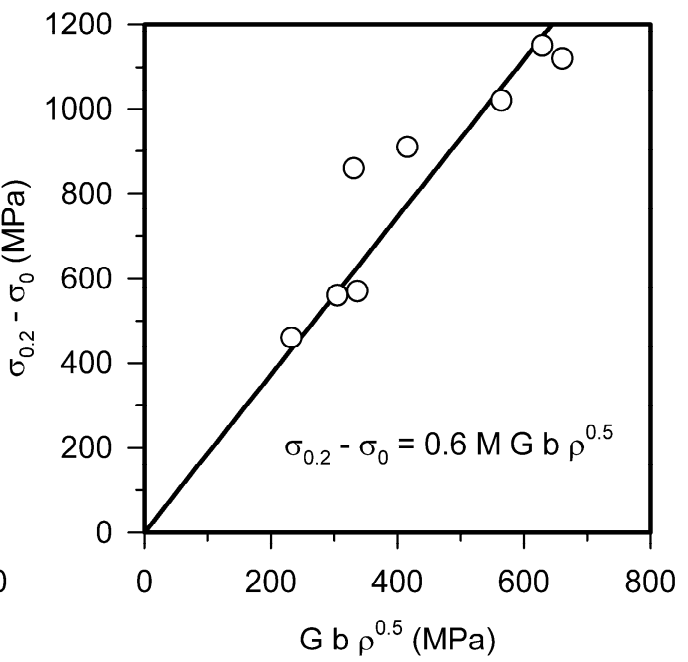

(b)

Figure 8. Relationship between the yield strength $\left(\sigma_{0.2}\right)$ and (a) the grain size $(D)$ or $(\mathbf{b})$ the dislocation density $(\rho)$ for a high-Mn steel subjected to cold rolling followed by annealing.

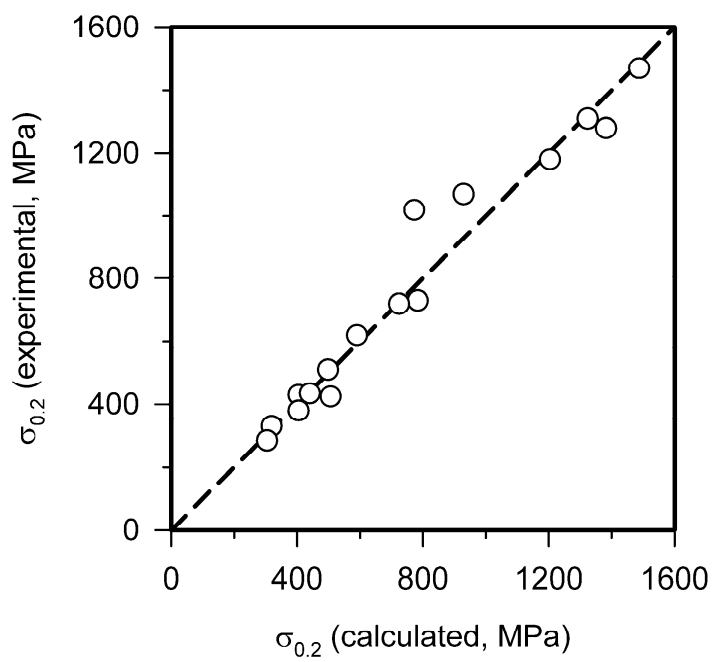

Figure 9. Relationship between the experimental yield strength and that calculated by Equation (5) for a high-Mn steel subjected to cold rolling and then annealed. 
Another important finding of the present study is the unique relationship between the microstructural/substructural parameters and the strength of the cold rolled and annealed samples irrespective of processing regimes. The strength of work hardened metallic materials was treated with a modified Hall-Petch type relationship including the term of dislocation strengthening $[16,17,34,35]$. However, a mutual correlation between the dislocation densities and grain boundary densities in metals and alloys subjected to large strain deformation made the estimation of individual strengthening mechanisms difficult $[32,36,37]$. In contrast, the present approach of fractional contributions of different strengthening mechanisms, which are originated from specific structural elements, into overall strength allows us to adequately predict the yield strength of steels with a mixture of various work hardened, recovered, and recrystallized microstructures.

\section{Conclusions}

The microstructure evolution and mechanical properties were studied in an Fe-18Mn-0.6C-1.5Al steel subjected to cold rolling and subsequent isochronal annealing for $30 \mathrm{~min}$. The main results can be summarized as follows.

1. The cold rolling resulted in significant strengthening of the steel. The hardness increased from 1900 to almost $6000 \mathrm{MPa}$ after rolling reduction of $80 \%$.

2. Annealing behavior was characterized by the development of recovery and recrystallization. Recovery took place during annealing at temperatures of 673 and $773 \mathrm{~K}$, leading to fractional softening below 0.2 . On the other hand, the static recrystallization readily developed during annealing at 873 and $973 \mathrm{~K}$, leading to fractional softening of about 0.8 .

3. The recrystallized grain size depended on annealing temperature and rolling reduction. An increase in the rolling reduction from $20 \%$ to $80 \%$ led to a decrease in the mean recrystallized grain size from about 8 to $1.6 \mu \mathrm{m}$ after subsequent annealing at $923 \mathrm{~K}$ and to $1.1 \mu \mathrm{m}$ after annealing at $873 \mathrm{~K}$.

4. The yield strength of the recovered and recrystallized steel samples, as well as partially recrystallized ones, could be expressed by a modified Hall-Petch type relationship taking into account the fractional contributions from grain size strengthening and dislocation strengthening.

Acknowledgments: This study was supported by the Ministry of Science and Education of Russian Federation under the Grant No. 14.575.21.0134 (RFMEFI57517X0134). Authors are grateful to the personal of the Joint Research Center, Technology and Materials, Belgorod State University for their assistance with instrumental analysis.

Author Contributions: Dmitri A. Molodov and Rustam Kaibyshev elaborated the research topic; Alexander Kalinenko and Pavel Kusakin designed and performed experiments; Andrey Belyakov, Dmitri A. Molodov, and Rustam Kaibyshev analyzed the obtained results; all co-authors discussed the paper.

Conflicts of Interest: The authors declare no conflict of interest.

\section{References}

1. Grässel, O.; Krüger, L.; Frommeyer, G.; Meyer, L.W. High strength Fe-Mn-(Al, Si) TRIP/TWIP steels development-Properties-Application. Int. J. Plast. 2000, 16, 1391-1409. [CrossRef]

2. Bouaziz, O.; Allain, S.; Scott, C.P.; Cugy, P.; Barbier, D. High manganese austenitic twinning induced plasticity steels: A review of the microstructure properties relationships. Curr. Opin. Solid State Mater. Sci. 2011, 15, 141-168. [CrossRef]

3. Kusakin, P.S.; Kaibyshev, R.O. High-Mn twinning-induced plasticity steels: Microstructure and mechanical properties. Rev. Adv. Mater. Sci. 2016, 44, 326-360.

4. De Cooman, B.C.; Estrin, Y.; Kim, S.K. Twinning-induced plasticity (TWIP) steels. Acta Mater. 2018, 142, 283-362. [CrossRef]

5. Hofmann, H.; Mattissen, D.; Schaumann, T.W. Advanced cold rolled steels for automotive applications. Steel Res. Int. 2009, 80, 22-28. [CrossRef] 
6. Nikulin, I.; Sawaguchi, T.; Kushibe, A.; Inoue, Y.; Otsuka, H.; Tsuzaki, K. Effect of strain amplitude on the low-cycle fatigue behavior of a new Fe-15Mn-10Cr-8Ni-4Si seismic damping alloy. Int. J. Fatigue 2016, 88, 132-141. [CrossRef]

7. Ryan, N.D.; McQueen, H.J. Dynamic softening mechanisms in 304 austenitic stainless steel. Can. Metall. Q. 1990, 29, 147-162. [CrossRef]

8. Belyakov, A.; Tikhonova, M.; Yanushkevich, Z.; Kaibyshev, R. Regularities of Grain Refinement in an Austenitic Stainless Steel during Multiple Warm Working. Mater. Sci. Forum 2013, 753, 411-416. [CrossRef]

9. Sakai, T.; Belyakov, A.; Kaibyshev, R.; Miura, H.; Jonas, J.J. Dynamic and post-dynamic recrystallization under hot, cold and severe plastic deformation conditions. Prog. Mater. Sci. 2014, 60, 130-207. [CrossRef]

10. Gill Sevillano, J.; Van Houtte, P.; Aernoudt, E. Large strain work hardening and textures. Prog. Mater. Sci. 1980, 25, 69-412. [CrossRef]

11. Frommeyer, G.; Brüx, U.; Neumann, P. Supra-ductile and high-strength manganese-TRIP/TWIP steels for high energy absorption purposes. ISIJ Int. 2003, 43, 438-446. [CrossRef]

12. Saeed-Akbari, A.; Mosecker, L.; Schwedt, A.; Bleck, W. Characterization and prediction of flow behavior in high-manganese twinning induced plasticity steels: Part I. mechanism maps and work-hardening behavior. Metall. Mater. Trans. A 2012, 43, 1688-1704. [CrossRef]

13. Kusakin, P.; Tsuzaki, K.; Molodov, D.A.; Kaibyshev, R.; Belyakov, A. Advanced thermomechanical processing for a high-Mn austenitic steel. Metall. Mater. Trans. A 2016, 47, 5704-5708. [CrossRef]

14. Kusakin, P.; Kalinenko, A.; Tsuzaki, K.; Belyakov, A.; Kaibyshev, R. Influence of cold forging and annealing on microstructure and mechanical properties of a high-Mn TWIP steel. Kov. Mater. 2017, 55, 161-167. [CrossRef]

15. Torganchuk, V.; Belyakov, A.; Kaibyshev, R. Effect of rolling temperature on microstructure and mechanical properties of 18\%Mn TWIP/TRIP steels. Mater. Sci. Eng. A 2017, 708, 110-117. [CrossRef]

16. Kusakin, P.; Belyakov, A.; Haase, C.; Kaibyshev, R.; Molodov, D.A. Microstructure evolution and strengthening mechanisms of Fe-23Mn-0.3C-1.5Al TWIP steel during cold rolling. Mater. Sci. Eng. A 2014, 617, 52-60. [CrossRef]

17. Yanushkevich, Z.; Belyakov, A.; Haase, C.; Molodov, D.A.; Kaibyshev, R. Structural/textural changes and strengthening of an advanced high-Mn steel subjected to cold rolling. Mater. Sci. Eng. A 2016, 651, 763-773. [CrossRef]

18. Sakai, T. Dynamic recrystallization microstructures under hot working conditions. J. Mater. Process. Technol. 1995, 53, 349-361. [CrossRef]

19. Belyakov, A.; Kimura, Y.; Adachi, Y.; Tsuzaki, K. Microstructure evolution in ferritic stainless steels during large strain deformation. Mater. Trans. 2004, 45, 2812-2821. [CrossRef]

20. Haase, C.; Barrales-Mora, L.A.; Molodov, D.A.; Gottstein, G. Tailoring the mechanical properties of a twinning-induced plasticity steel by retention of deformation twins during heat treatment. Metall. Mater. Trans. A 2013, 44, 4445-4449. [CrossRef]

21. Humphreys, F.J.; Hatherly, M. Recrystallization and Related Annealing Phenomena, 2nd ed.; Elsevier: Oxford, UK, 2004; pp. 215-268. ISBN 0-08-044164-5.

22. Hall, E.O. The deformation and ageing of mild steel: III discussion of results. Proc. R. Soc. Lond. Ser. B 1951, 64, 747-753. [CrossRef]

23. Petch, N.J. The cleavage strength of polycrystals. J. Iron Steel Inst. 1953, 174, 25-28.

24. Yanushkevich, Z.; Belyakov, A.; Kaibyshev, R.; Haase, C.; Molodov, D.A. Effect of cold rolling on recrystallization and tensile behavior of a high-Mn steel. Mater. Charact. 2016, 112, 180-187. [CrossRef]

25. Shakhova, I.; Dudko, V.; Belyakov, A.; Tsuzaki, K.; Kaibyshev, R. Effect of large strain cold rolling and subsequent annealing on microstructure and mechanical properties of an austenitic stainless steel. Mater. Sci. Eng. A 2012, 545, 176-186. [CrossRef]

26. Odnobokova, M.; Belyakov, A.; Enikeev, N.; Molodov, D.A.; Kaibyshev, R. Annealing behavior of a 304L stainless steel processed by large strain cold and warm rolling. Mater. Sci. Eng. A 2017, 689, 370-383. [CrossRef]

27. Mecking, H.; Kocks, U.F. Kinetics of flow and strain-hardening. Acta Metall. 1981, 29, 1865-1875. [CrossRef]

28. Estrin, Y.; Toth, L.S.; Molinari, A.; Brechet, Y. A dislocation-based model for all hardening stages in large strain deformation. Acta Mater. 1998, 46, 5509-5522. [CrossRef] 
29. Haase, C.; Barrales-Mora, L.A.; Roters, F.; Molodov, D.A.; Gottstein, G. Applying the texture analysis for optimizing thermomechanical treatment of high manganese twinning-induced plasticity steel. Acta Mater. 2014, 80, 327-340. [CrossRef]

30. Ardell, A.J. Precipitation hardening. Metall. Trans. A 1985, 16, 2131-2165. [CrossRef]

31. Ma, K.; Smith, T.; Hu, T.; Topping, T.D.; Lavernia, E.J.; Schoenung, J.M. Distinct hardening behavior of ultrafine-grained Al-Zn-Mg-Cu alloy. Metall. Mater. Trans. A 2014, 45, 4762-4765. [CrossRef]

32. Shakhova, I.; Belyakov, A.; Yanushkevich, Z.; Tsuzaki, K.; Kaibyshev, R. On strengthening of austenitic stainless steel by large strain cold working. ISIJ Int. 2016, 56, 1289-1296. [CrossRef]

33. Calcagnotto, M.; Ponge, D.; Demir, E.; Raabe, D. Orientation gradients and geometrically necessary dislocations in ultrafine grained dual-phase steels studied by 2D and 3D EBSD. Mater. Sci. Eng. A 2010, 527, 2738-2746. [CrossRef]

34. Hansen, N. Hall-Petch relation and boundary strengthening. Scr. Mater. 2004, 51, 801-806. [CrossRef]

35. Morozova, A.; Kaibyshev, R. Grain refinement and strengthening of a Cu-0.1Cr-0.06Zr alloy subjected to equal channel angular pressing. Philos. Mag. 2017, 97, 2053-2076. [CrossRef]

36. Starink, M.J. Dislocation versus grain boundary strengthening in SPD processed metals: Non-causal relation between grain size and strength of deformed polycrystals. Mater. Sci. Eng. A 2017, 705, 42-45. [CrossRef]

37. Yanushkevich, Z.; Dobatkin, S.V.; Belyakov, A.; Kaibyshev, R. Hall-Petch relationship for austenitic stainless steels processed by large strain warm rolling. Acta Mater. 2017, 136, 39-48. [CrossRef]

(C) 2017 by the authors. Licensee MDPI, Basel, Switzerland. This article is an open access article distributed under the terms and conditions of the Creative Commons Attribution (CC BY) license (http://creativecommons.org/licenses/by/4.0/). 